\title{
O Machismo e a Visão Científica e Cultural dos alunos do Ensino Médio InTegrado de uma Rede de Ensino Pública Federal
}

\author{
The Machism and The Scientific And Cultural Vision OF THE \\ Integrated High School Students of a Federal Public Education \\ NETWORK
}

\author{
Daniela Copetti Santos \\ Doutora em Ciências Biológicas - Bioquímica pela Universidade Federal do Rio \\ Grande do Sul (UFRGS)- Porto Alegre- RS- Brasil \\ Instituto Federal de Educação, Ciência e Tecnologia Farroupilha - Campus Santa \\ Rosa. \\ daniela.copetti@iffarroupilha.edu.br \\ (1) Luciane Carvalho Oleques \\ Doutora em Educação em Ciências: Química da vida e saúde pela Universidade \\ Federal de Santa Maria (UFSM)- Santa Maria- RS- Brasil \\ Instituto Federal de Educação, Ciência e Tecnologia Farroupilha - Campus Santa Rosa \\ luciane.oleques@iffarroupilha.edu.br \\ Juliane Oberoffer Santos da Rosa \\ Especialização em educação especial e inclusiva pelo Centro Universitário \\ Internacional Uninter - Brasil. \\ Instituto Federal de Educação, Ciência e Tecnologia Farroupilha - Campus Santa \\ Rosa. \\ juliano.rosa@iffarroupilha.edu.br
}

Resumo: Este estudo propõe a busca pelo conhecimento na perspectiva da diversidade sexual, sexualidade e relações de gênero. Utiliza-se metodologias ativas realizadas por alunos do Ensino Médio Integrado do Instituto Federal Farroupilha-Campus Santa Rosa, tendo como suporte o componente curricular de Biologia ministrado e orientado pelas autoras. A metodologia utilizada surgiu da própria criatividade deles, tendo sida desenvolvida em três momentos. No primeiro momento uma revisão bibliográfica, no segundo e terceiro momento, entrevistas abertas com profissionais envolvidos diretamente no assunto tratado nesse trabalho e que atuam no município da região Noroeste do Rio Grande do Sul. Após o trabalho ser desenvolvido verificamos que os alunos consideram que Machismo é uma ideia ultrapassada, que afirma a superioridade do homem perante a mulher, considera-se toda e qualquer forma de violência contra a mulher. Conclui-se que é fundamental o diálogo, rever argumentos, questionar-se sobre possíveis verdades tradicionais e inserir o contexto no cotidiano.

Palavras-chave: Biologia. Diversidade sexual. Ensino Médio Integrado.

\begin{abstract}
This study proposes the search for knowledge in the perspective of sexual diversity, sexuality and gender relations. We use active methodologies performed by students of the integrated High School of the Federal Institute Farroupilha-Campus Santa Rosa, having as support the curricular component of biology ministed and guided by the authors. The methodology used emerged from their own creativity, having AIDS developed in three moments. In the first moment a bibliographic review, in the second and third moment, open interviews with professionals directly involved in the subject treated in this work and working in the city of the northwest region of Rio Grande do Sul. After the work was developed we found that the students think that Machismo is an outdated idea, which affirms the superiority of man before the woman, it is considered every form of violence against women. It is concluded that dialogue is fundamental, reviewing arguments, questioning about possible traditional truths and inserting the context in everyday life.
\end{abstract}

Keywords: Pedagogical practices; Reading and writing; Inclusive education. 


\section{Introdução}

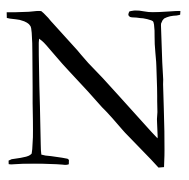

o Brasil, houve momentos nas constituições do país que a igualdade não existia em seu sentido formal, legitimando certas formas de discriminação das minorias sociais. Depois de um longo período de violações dos direitos fundamentais e censura da liberdade, finalmente, é promulgada a Constituição Federal de 1988 (BRASIL, 1988).

A sobreposição de que os homens são superiores às mulheres é uma ideia impregnada na história do Brasil. A agressão não vinha somente da sociedade, mas do Estado, que apropriado do machismo, fomentava a diferença entre os gêneros. Nesse contexto, surgiu a necessidade de instigarmos os alunos do Ensino Médio Integrado do Instituto Federal Farroupilha (IFFar) - Campus Santa Rosa a irem em busca de um maior conhecimento que ultrapassassem os muros escolares, com ênfase em temas atuais, os quais são alvos de muitas discussões e contradições, conforme alguns cientistas relatam. Entre os temas propostos, foi dada maior ênfase a métodos contraceptivos, infecções sexualmente transmissíveis (IST), gravidez na adolescência, violência contra a mulher, gênero e suas diversidades e, machismo e feminismo.

Com a escolha desses temas foi proposto pelas autoras desse trabalho que o mesmo fosse desenvolvido por duas turmas de primeiros anos dos Técnicos Integrados do IFFar. Em cada uma dessas turmas havia aproximadamente trinta (30) alunos, os quais foram separados em dez grupos diferentes, conforme o assunto sorteado. Os alunos deveriam formar grupos mistos, ou seja, deveria haver alunos tanto de uma turma quanto da outra. Nesse grupo que teve como foco o Machismo, participaram seis (6) alunos, sendo (3) três de cada turma. Atuaram nesse projeto, além das autoras, as quais eram as professoras dessas turmas e ministrantes da disciplina de Biologia, uma técnica educacional, presidente do Núcleo de Gênero e Diversidade Sexual (NUGEDIS) do IFFar.

O objetivo do trabalho era fazer com que os alunos a partir da sua curiosidade, criatividade, da capacidade científica, da pesquisa e do entrosamento com os seus colegas buscassem aprender, sobre esses assuntos, os quais estão presentes cada vez mais no cotidiano desses alunos. Não poderiam ser utilizados assuntos prontos e retirados de livros.

O grupo responsável pelo tema desse trabalho a partir de conversas prévias resolveu utilizar como metodologia três momentos diferentes. No primeiro momento houve uma pesquisa através de referenciais teóricos o que foi acompanhado e sugerido pelas professoras, nesse momento eles puderam conhecer a contextualização que se faz em torno do "Machismo". No segundo e terceiro momento foram realizadas algumas entrevistas com profissionais que atuam diretamente com esse assunto, uma conselheira tutelar e uma oficial de justiça.

Após o desenvolvimento da metodologia ativa mencionada anteriormente verificou-se que os alunos consideram que "Machismo é uma ideia ultrapassada, que afirma a superioridade do homem perante a mulher. É 
toda e qualquer forma de violência contra a mulher. O machismo está presente na vida de todas as mulheres e se apresenta de todas as maneiras desde a infância".

Dessa forma conclui-se que é fundamental o diálogo, rever argumentos, questionar-se sobre possíveis verdades tradicionais e inserir o contexto no cotidiano.

\section{Desmistificando o machismo}

Desde os primeiros movimentos femininos - do fim do século XIX e início do século XX- até a atualidade, muitos foram os avanços na promoção dos direitos das mulheres e no estímulo à igualdade de gênero.

O artigo 113 da CF/ 88 (BRASIL, 1988) determina que todos são iguais perante a lei. Não haverá privilégios, nem distinções, por motivo de nascimento, sexo, raça, profissões próprias, porém durante a história do nosso país e do mundo muitas foram as lutas e reivindicações das mulheres por direitos políticos, sociais, trabalhistas, civis e intelectuais. Entre os exemplos citados em que observamos a discriminação contra a mulher está na própria presença das mulheres em sala de aula, o que até o ano de 1827, não era permitido que elas tivessem acesso nem ao ensino primário, outro exemplo citado é o do voto, até 1927, a mulher sequer tinha direito a ir às urnas, isso era um direito exclusivo do homem. No meio intelectual observamos nos dias de hoje que a mulher vem crescendo em sua formação acadêmica, porém ao observamos os espaços ocupados por homens e mulheres após as suas formações, ainda observamos uma discrepância entre eles. As mulheres representam 47\% das lideranças dos grupos de pesquisa, $46 \%$ dos docentes universitários e apenas $36 \%$ dos pesquisadores reconhecidos no mundo científico (FRANÇA, 2018).

A fim de amenizar essas questões em âmbito escolar o Plano Nacional de Educação (PNE) (BRASIL, 2014) institui entre as suas diretrizes a erradicação de todas as formas de discriminação e a promoção dos princípios do respeito aos direitos humanos e à diversidade.

Observa-se que apesar da criação de várias leis sancionadas para diminuir a discriminação contra a mulher ainda existem disparidades nos dias de hoje em nossa sociedade. A sociedade ocidental tem assistido a inúmeros casos de machismo impregnado nas falas, condutas e práticas sociais por parte de muitas pessoas que nela vivem. Esse comportamento não é restrito a homens machistas, mas, também, a mulheres machistas. Esta prática é aprendida em várias instituições sociais, às quais se destacam a família, a escola e a mídia, por exemplo (OLIVEIRA e MAIO, 2016).

Segundo esses autores, discorrer sobre o machismo é simples e complexo ao mesmo tempo. Simples porque existem vários exemplos práticos na sociedade (ocidental ou oriental), sendo facilmente identificados; e complexo porque demandam estudos científicos, culturais, políticos para escrever com propriedade, além de ser um tema que poucas pessoas conseguem discutir durante um período longo da 
vida, ou seja, pouco se fala nas escolas e pouco se discute na família (de forma emancipadora, humanista, respeitosa, conforme será analisado adiante).

Mendes (2010a,b) em sua perspectiva revela que o termo ideologia de gênero pode ser substituído, sem nenhum prejuízo, pelo termo "machismo" porque, como uma forma de discurso, interpela e qualifica os sujeitos e suas identidades sociais, de acordo com os seus gêneros, relegando à mulher um lugar social inferior e de submissão ao homem.

As implicações dessa ideologia na sociedade são objetivas e revelam quando, por exemplo, se observa que o Brasil ocupa atualmente o $7^{\circ}$ lugar no ranking dos países que mais mata mulheres em todo o mundo. O detalhe é que 27,1\%dessas mulheres foram assassinadas dentro de suas próprias casas e na maioria dos casos, pelos seus próprios parceiros (WAISELFISZ, 2015).Segundo Cerqueira et al. (2017, p. 37), a violência contra a mulher antecede o seu assassinato, isso quer dizer que "até chegar a ser vítima de uma violência fatal, essa mulher foi vítima de uma série de outras violências de gênero, [...] [tais como] violência psicológica, patrimonial, física ou sexual". Sobre esse aspecto, 29\% das mulheres brasileiras relataram já ter sofrido algum tipo de violência, no entanto apenas $11 \%$ delas procuraram uma delegacia. Trata-se de uma realidade que não só se mantém como tende a se aprofundar uma vez que a taxa de homicídio de mulheres avançou 7,3\% no Brasil, entre 2005 e 2015, e que o cenário contemporâneo apresenta um avanço dos discursos conservadores (idem).

\section{Machismo em um município da Região Noroeste do sul do país}

Após a pesquisa bibliográfica, a fim de esclarecer algumas dúvidas pertinentes ao trabalho, e conhecer mais como o tema é tratado no município foram realizadas duas entrevistas, uma com a Conselheira Tutelar e a outra com a oficial escrevente. A Conselheira Tutelar explicou como o Conselho Tutelar age perante as vítimas dessa situação. "O Conselho Tutelar no cumprimento de suas atribuições, trabalha diretamente com pessoas que passam situacões de crises e dificuldades, inclusive devido ao Machismo." Como exemplo ela citou filhas que são extremamente atingidas pelos pais, namoradas na fase da adolescência que sofrem maustratos pelos seus namorados. Nessa conversa a profissional esclareceu que "a educaşão contra a cultura machista deve comesar dando bons exemplos e dialogando desde o primeiro dia de existência, não é somente na adolescência ou até mesmo na fase adulta que a situação poderá ser revertida, muitas vezes já virou uma situação crônica que fica difícil reverter à situação". Temos como ambientes de proteção a Delegacia Especial de Atendimento à Mulher (DEAM) que ajuda a romper o silêncio das mulheres. Proporcionam o registro da ocorrência policial e a solicitação de medidas protetivas, como o afastamento do agressor do lar. A DEAM possui assistente social, psicólogos estando diretamente ligada ao Sistema Judiciário e inclusive levando a vítima para um abrigo longe daquela violência que vinha sofrendo até o presente momento. O Centro de Referência Regional de Atendimento à Mulher é um espaço aonde elas recebem todo o acolhimento, com toda a atenção psicológica, social, orientação e encaminhamento jurídico à mulher em situação de violência.

Quando contatada a primeira pergunta que fizeram a oficial escrevente foi "Por que as mulheres que sofreram violência não se libertam/separam do marido agressor? E três fatores foram enumerados: $1^{\circ}$ Relação de dependência 
econômica, $2^{\circ}$ Chantagem emocional e $3^{\circ}$ Ameaça aos filhos. Segundo Paes (2015), além de enfrentarem a divisão desigual do trabalho e assumirem a maioria das atividades domésticas, ainda recebem 30\% a menos do que os homens como remuneração. Situações como estas, que causam dependência financeira e vulnerabilidade em relação aos seus parceiros, fazem com que grande parte delas se submeta à violência doméstica. A Cartilha Maria da Penha e Direitos da Mulher (BRASIL, 2011) do Ministério Público trata a violência em 5 tipos diferentes e uma delas é a violência sexual que afirma que qualquer conduta que constranja a presenciar, manter ou participar de relação sexual não desejada, mediante intimidação, ameaça, coação ou uso da força; que a induza a comercializar ou utilizar de qualquer modo de contraceptivo ou force ao matrimônio, à gravidez, ao aborto ou à prostituição, mediante coação, chantagem, suborno ou manipulação; ou que limite ou anule os seus direitos sexuais reprodutivos.

O feminicídio tem como o fundamento jurídico maior a proteção da mulher contra as atrocidades de comportamento do homem. A supremacia do homem, historicamente falando, sempre esteve patente desde a Grécia antiga, quando a figura da mulher equivaleria a de um escravo, bem como na Roma antiga, onde o homem exercia o pleno poder, não somente sobre a mulher, mas também sobre os filhos, servos e escravos (pater-famílias).

\section{O machismo sob a visão dos alunos do Instituto Federal Farroupilha}

Todos esses relatos aqui expostos foram apresentados em sala de aula para os demais colegas e professores, no final da explanação foi aberto um tempo para perguntas e questionamentos sobre o trabalho desenvolvido e chegou-se à conclusão de que a grande maioria cresceu com preconceitos "masculinos", como roupas de heróis e de cores masculinas, bonecos, carrinhos etc. Hoje, consideram que a mente está aberta e não veem problema em um garoto brincar de bonecas ou usar roupas rosas se ele gostar. $\mathrm{O}$ machismo vem da infância e acaba fazendo com que os filhos continuem assim quando adultos. É necessário dialogar sempre, rever alguns argumentos que possam estar associados ao Machismo, é necessário questionar-se sobre possíveis verdades tradicionais, sempre buscando o conhecimento de pessoas especializadas no assunto. $\mathrm{Na}$ escola, em casa é necessário inserir o contexto no cotidiano e debater a respeito, a principal ferramenta de combate ao preconceito é a informação.

Com o desenvolvimento da revisão bibliográfica e após as entrevistas realizadas verificamos que os alunos acham que "Machismo é uma ideia ultrapassada, que afirma a superioridade do homem perante a mulher. É toda e qualquer forma de violência contra a mulher. O machismo está presente na vida de todas as mulheres e se apresenta de todas as maneiras desde a infância". Nessa pesquisa eles foram além e verificaram a contextualização do "Machismo" na escola, concluindo que: "Percebemos que isso é uma coisa cultural, a criança acaba aprendendo esse comportamento com os adultos. Acaba-se vivenciando na sala de aula situações do tipo "Menino não pode brincar de boneca ou de cozinhar" "Menina não pode dirigir". Tenta-se sempre questionar a criança, fazendo com que ela a partir desses questionamentos comece a pensar essa questão. Isso é um conceito que precisa ser desconstruído, percebemos que já tem mudanças significativas, mas não 
é de uma hora para outra que irá mudar. "Acreditamos que quanto menor a criança mais fácil de começar a trabalhar esses assuntos. ”

\section{Considerações finais}

A metodologia ativa usada pelos estudantes nos mostrou em primeiro lugar o nível de curiosidade deles, em segundo a capacidade científica, através da busca do novo, do conhecimento por um tema tão relevante como esse. Tema esse que muitas vezes não é explorado nas escolas, devido ao próprio preconceito em torno do mesmo e devido a rigidez nos planos de ensino das devidas disciplinas que devem ser cumpridos em tempo hábil. Dessa forma deixamos de lado assuntos que muitas vezes encontram- se latentes em nossa sociedade, que devem ser enfrentados no nosso cotidiano, que muitas vezes estão diante dos nossos olhos e que na maioria das vezes não damos a maior importância.

\section{Referências}

BRASIL, Ministério Público Federal/ Procuradoria Federal dos Direitos do Cidadão. Lei Maria da Penha \& Direitos da Mulher. Brasil. 2011. Disponível em: https://pt.slideshare.net/silvana9881/cartilhamariadapenhaedireitosdamulherpfdcmpf Acesso em: 03 mar 2019.

BRASIL. Plano Nacional de Educação. Lei no . 13005/2014. 2014. Disponível em: <www.planalto.gov.br/ccivil_03/_ato2011-2014/2014/lei/113005.htm>. Acesso em: 28 fev. 2019.

CERQUEIRA, D. et al. Atlas da violência 2017. Rio de Janeiro: IPEA e Fórum Brasileiro de Segurança Pública, 2017. Disponível em: http://www.ipea.gov.br/portal/images/170602_ atlas_da_violencia_2017.pdf. Acesso em: 4 mar. 2019.

FRANÇA, V.V. Machismo e seu impacto na carreira de mulheres cientistas. Equidade na Ciência. São Paulo. UNESP, ed. 100, 2018. Disponível em:

http://www.unespciencia.com.br/revista/UC100/UC100_Mulheres_Ciencia.pdf Acesso em: 04 mar 2019.

MENDES, D. A ideologia de gênero na publicidade contemporânea. Mediações-Revista de Ciências Sociais, v. 15, n. 1, p. 241-257, 2010b. Disponível em: http://www.uel.br/Educação em Revista|Belo Horizonte |v.34 | e190810| 201828 revistas/uel/index.php/mediacoes/article/view/4291/5945. Acesso em: 05 jan. 2019.

MENDES, D. Ideologia de gênero: uma contribuição marxista para a teoria feminista. IV Simpósio Lutas Sociais na América Latina, Universidade Estadual de Londrina, Paraná, 2010a. Disponível em: 
http://www.uel.br/grupo-pesquisa/gepal/anais_ivsimp/gt7/1_deboramendes.pdf. Acesso em: 05 jan. 2019.

OLIVEIRA, de M., MAIO, R. S. “Você tentou fechas as pernas?”- A cultura machista impregnada nas práticas sociais. 2016. Disponível em: https://www.e-

publicacoes.uerj.br/index.php/polemica/article/view/25199/18031 Acesso em: 04 mar 2019.

PAES, MAD. Feminicídio: uma questão de igualdade e gênero. disponível em

http://www.conjur.com.br/2015-jan-10/mariana-paes-feminicidio-questao-igualdade-genero. Acesso em: 29 de jan de 2019.

WAISELFISZ, J. J. Mapa da violência 2015: homicídio de mulheres no Brasil. BrasíliaDF: Flacso, 2015. Disponível em: https://www.mapadaviolencia.org.br/pdf2015/ MapaViolencia_2015_mulheres.pdf. Acesso em: 15 jan. 2018.

Recebido em: 08 mar. 2019 / Aprovado em: 31 out. 2019

\section{Para referenciar este texto}

SANTOS, Daniela copetti; OLEQUES, Luciane Carvalho; ROSA, Juliane Oberoffer Santos da. O Machismo e a visão Científica e Cultural dos alunos do Ensino Médio Integrado de uma Rede de Ensino Pública Federal. Cadernos de Pós-graduacão, São Paulo, v. 18, n.2, p. 235-241, jul./dez. 2019. Disponível em: $<$ https://doi.org/10.5585/cpg.v18n2.13210>. 